\title{
PARÂMETROS PROJETUAIS PARA A IMPLANTAÇÃO DE SANITÁRIOS SECOS DESIDRATADORES COM DESVIO DE URINA (SSDDU)
}

\section{PROJECT PARAMETERS FOR THE DEVELOPMENT OF URINE DIVERSION DEHYDRATION TOILETS (UDDT)}

\author{
Alexandra Lima Demenighi, M.Sc. (UFSC); \\ Luis Alberto Gómez, Dr. (UFSC); \\ Rodrigo Vargas Souza, M.Sc. (UFSC)
}

\author{
Palavras Chave \\ Parâmetros Projetuais; Sanitário Seco Desidratador; Saneamento Ecológico \\ Key Words \\ Design Parameters; Urine Diversion Dehydration Toilets; Ecological Sanitation
}

\section{RESUMO}

O Sanitário Seco Desidratador com Desvio de Urina difere dos sistemas convencionais por não utilizar água para seu funcionamento. Neste sistema os "dejetos" são considerados recursos, constituindo valiosos fertilizantes para o solo, fechando o ciclo de nutrientes. Neste sentido, o presente artigo tem como objetivo identificar os parâmetros projetuais que envolvem a implantação deste sistema. Para isso, foram realizados estudos de caso em locais que utilizaram este sistema como opção de saneamento. Como resultado, se definiu uma tipologia de sanitário seco adaptado para as condições brasileiras, especificando os componentes de projeto, sua operação e as recomendações para o gerenciamento e tratamento das fezes e urina do sistema de coleta e armazenamento. Os resultados obtidos demonstram que a tecnologia possibilita a constituição de um sistema limpo, seguro e conveniente, provocando uma redefinição na concepção atual de gestão de "resíduos" humanos, que desperdiçam água sendo responsáveis por graves danos ambientais cada vez mais assistidos.

\section{ABSTRACT}

The Urine Diversion Dehydration Toilets differs from conventional systems because it does not use water for its operation. In this system the "wastes" are considered resources, constituting valuable fertilizers for the soil, closing the nutrient cycle. In this sense, this work aims to identify the design parameters that involve the implementation of this system. For this, case studies were performed in places that used this system as a sanitation option. As a result, a typology of dry toilet adapted to the Brazilian conditions was defined, specifying the project components, their operation and the recommendations for the management and treatment of the human feces and urine of the collection and storage system. The results demonstrate that the technology enables the constitution of a clean, safe and convenient system, provoking a redefinition in the current management concept of human "wastes", which waste water and are responsible for serious environmental damages that are increasingly being watched. 


\section{INTRODUÇÃO}

A configuração atual para a gestão dos sistemas de esgoto, baseada em sistemas centralizados na forma de grandes estações de tratamento tem demonstrado dificuldades em sua realização. Altos custos operacionais e de manutenção, alta demanda de capital, além do elevado consumo energético em seu manejo, são alguns argumentos que a configuram como "tecnologia do final do tubo". No entanto, esta concepção linear ainda continua sendo adotada na ótica do saneamento, surgindo assim, à necessidade de se buscar novos sistemas a favor da conservação dos recursos naturais e promoção da saúde pública.

A difícil tarefa de melhorar o acesso universal ao saneamento é ainda complicada pelo consenso de abordagens convencionais - banheiros com descarga conectados a centrais de tratamento de esgotos que os despejam em mananciais locais - prática esta, que tem se mostrado econômica e ambientalmente insustentável.

Dentro desse contexto, se justifica esta pesquisa, na necessidade de contribuir com estratégias de projetos de saneamento que abrangem todos os aspectos da sustentabilidade, identificando os parâmetros projetuais que envolvem a implantação de sanitários secos.

Um sistema de saneamento seco difere dos sistemas convencionais por não utilizar água para seu funcionamento. Existem diversos tipos de sanitários secos, alguns construídos no local e outros industrializados e até automatizados, mas todos têm um objetivo comum: transformar os excrementos humanos, em um material higienicamente seguro para ser devolvido ao solo em forma de fertilizante.

Os sanitários secos desidratadores com desvio da urina (SSDDU) - derivado da sigla em inglês UDDTs Urine Diversion Dehydration Toilets) - serão alvo desta pesquisa. Estes sanitários coletam a urina e as fezes separadamente a partir de um assento especial. As fezes são coletadas em recipientes e armazenadas por um período de tempo prolongado a fim de desidratarem, reduzido a quantidade de organismos patogênicos e possibilitando seu manuseio com segurança. Esta nova perspectiva no contexto do saneamento oferece uma filosofia de lidar com aquilo que é atualmente considerado resíduo. Pois, devido ao alto teor de nutrientes presentes nas fezes e urina humanas, elas passam a serem consideradas recursos, onde é encorajado seu reuso, devolvendo o material ao solo na forma de adubo, contribuindo assim, para preservar a fertilidade na agricultura, garantindo a segurança alimentar.
Desta forma, deixa-se de lado a concepção linear na produção de esgoto, a qual atinge diretamente o meio ambiente, muitas vezes causando danos irreversíveis e parte-se para uma proposta holística, tentando com isso assemelhar-se aos ciclos da natureza.

Este sistema por não utilizar água para diluir nem transportar as fezes, não esta ligado a uma rede de esgoto. Consequentemente, não contamina o subsolo nem os cursos de água, possibilitando preservar este elemento essencial à vida. Os excrementos, após tratamento adequado, são utilizados como fertilizantes, devolvendo os nutrientes ao solo, fechando assim, o ciclo de nutrientes.

\section{SANEAMENTO ECOLÓGICO, CICLO DE NUTRIENTES E SANITÁRIO SECO}

O objetivo principal de um sistema de saneamento segundo a Aliança de Saneamento Sustentável (Sustainable Sanitation Alliance - SuSanA, 2011) é proteger e promover a saúde humana assegurando um ambiente saudável e neutralizando o ciclo de disseminação de doenças. Para ser sustentável, um sistema de saneamento deve ser não apenas economicamente viável, mas socialmente aceitável e apropriado do ponto de vista tecnológico e institucional. Deve, adicionalmente, proteger o ambiente e os recursos naturais.

Harremoes (1999), ainda argumenta quando estabelece alguns elementos, os quais ele chama de novos paradigmas e, entre eles, o fato de que um sistema não é sustentável enquanto utiliza água tratada para transportar matéria. Ele reforça, ainda, o sentido da recirculação com reuso e afirma que: "a solução é o saneamento com pequeno consumo de água, o que já é conhecido há muito tempo, mas que ainda não se consegue implantar. As razões para a falta de sucesso estão associadas com atitudes, cultura e educação: é um problema social mais do que um problema técnico".

Diante da problemática associada à implantação de sistemas centralizados de esgoto e a utilização de fluxo de água para a condução dos dejetos, a alternativa utilizada por alguns países em desenvolvimento que não podem pagar pelos serviços de descarga hídrica é a utilização de latrinas (Figura 01). 


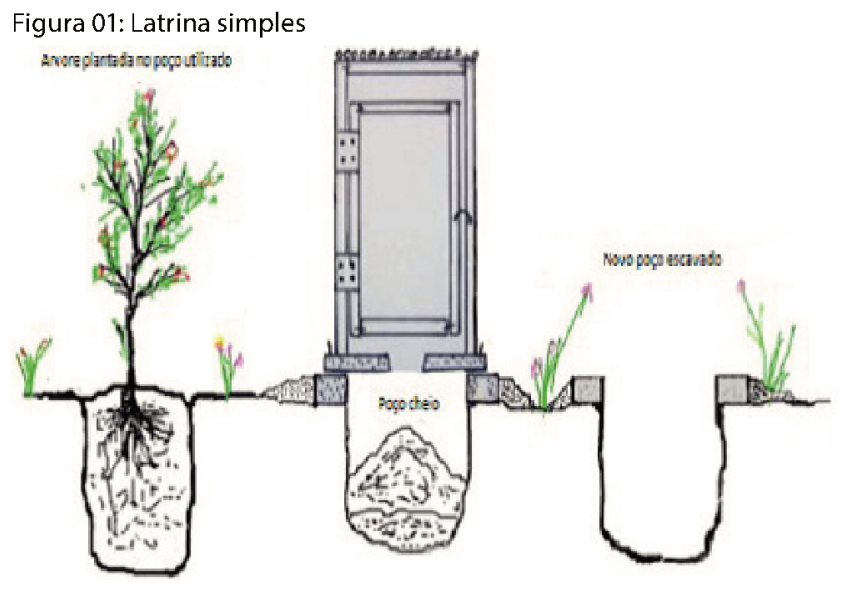

Fonte: Morgan (2007)

Como afirmam Calvert et al (2004), estes sistemas utilizam muito pouca água para seu funcionamento, mas apresentam algumas desvantagens, pois para evitar a contaminação das águas não podem ser implantados em locais onde o nível do lençol freático seja alto, em solos rochosos e em áreas periodicamente alagadas. Problemas com maus odores, moscas e a desvantagem de ter que fazer uma nova escavação com a saturação do poço existente são outras complicações.

Outra desvantagem desta tecnologia é que são construídas originalmente para a eliminação das fezes e não para reutilização das mesmas. Uma quantidade substancial de nutrientes, especialmente nitrogênio, é perdida por percolação ou evaporação (HEEB, 2007).

Diante disso, uma nova perspectiva no contexto do saneamento denominada Ecological Sanitation Eco-San, derivado da abreviação em língua inglesa de Saneamento Ecológico, oferece uma filosofia de lidar com aquilo que é atualmente considerado resíduo. Esta abordagem cíclica (Figura 2) considera os excrementos humanos como recursos.

Figura 02: O ciclo da excreta

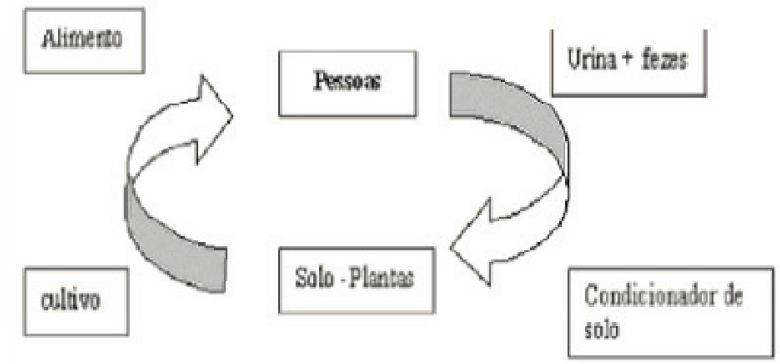

Fonte: Esrey et al., (1999).

No conceito eco-san, a solução ideal para as águas residuais, pelas diferentes características que apresentam, é separá-las em três componentes: fezes, urina e águas cinzas, pois assim podem ser mais facilmente tratadas separadamente. As águas cinzas podem ser separadas na origem, pois devido ao seu baixo grau de poluição é muito mais fácil de tratar do que as negras e amarelas (HEEB, 2007).

A urina e as fezes são coletadas e armazenadas no local, recebendo o tratamento necessário, até que estejam livres dos organismos patogênicos, podendo ser devolvidas ao solo na forma de nutrientes. Ao contrário das abordagens convencionais de saneamento que quebram o ciclo de nutrientes apresentando um fluxo linear, os sistemas eco-san têm o objetivo, além de promover a destruição dos organismos patogênicos dos excrementos, evitar a poluição, capturar os nutrientes e reciclá-los de volta ao solo. Contribui-se assim, para preservar a fertilidade na agricultura, garantindo a segurança alimentar.

A composição da matéria fecal e urina humana demonstram um potencial para aplicação agrícola devido a presença de nitrogênio, fósforo e potássio ( $N, P, K)$, principais nutrientes para as plantas. Estes produtos geralmente não estão contaminados com substâncias tóxicas da indústria química, mas ainda assim devem ser tratados para reduzir os índices de patógenos para um nível seguro.

A urina contém a maior parte dos nutrientes que são essenciais na agricultura nitrogênio, fósforo e potássio ( $N$, $\mathrm{P}, \mathrm{K}$ ), em quantidades bastante adequadas para o uso direto na produção (ESREY et al., 1999). Estima-se que este tipo de reciclagem dos nutrientes poderia substituir de 20 a $25 \%$ dos fertilizantes químicos comerciais atualmente (GONÇALVES, 2006).

Quando se analisa o sistema de coleta em separado, visando a recuperação da urina, pode-se inferir que existe uma economia de energia ao se utilizar esta urina como insumo agrícola. Esta economia se traduz na diminuição e/ou substituição de compostos de nitrogênio presentes em fertilizantes químicos, diminuindo assim o gasto energético necessário para todo o processo de obtenção destes compostos, podendo chegar a uma economia de $36 \%$ da energia gasta (JÖNSSON et al., 2004).

A própria diminuição da energia necessária aos processos de nitrificação, desnitrificação e remoção de fósforo seria evitada. Se toda a urina produzida fosse coletada em separado, cerca de 80 a $85 \%$ das emissões de compostos de nitrogênio e $50 \%$ de compostos de fósforo deixariam de contaminar e comprometer a qualidade dos corpos de água (JÖNSSON et al., 2004).

Mesmo contendo menos nutrientes que a urina, as fezes representam um valioso condicionador de solos. 
Como afirma Esrey et al (1999), as fezes humanas são compostas por matéria orgânica não digerida, como as fibras de carbono. A quantidade total excretada por um ser humano em um ano é de 25 a $50 \mathrm{Kg}$ que por sua vez compreendem $550 \mathrm{~g}$ de nitrogênio, $180 \mathrm{~g}$ de Fósforo e 370 $\mathrm{g}$ de potássio. Depois de receber um tratamento adequado para a destruição dos patogênicos, o material pode ser aplicado ao solo resultando uma série de benefícios.

Schonning e Stenstrom (2004), ainda afirmam que a presença dos organismos causadores de doenças na excreta humana é o resultado da infecção dos indivíduos. Este tipo de infecção não se manifesta necessariamente com sintomas clínicos, mas podem conduzir a uma excreção dos patógenos em questão. Para os organismos que infectam o trato gastrointestinal, esta excreção se dá basicamente através das fezes. Organismos patogênicos geralmente compreendem as bactérias, vírus e parasitas, como vermes, amebas e protozoários, que invadem o organismo e causam doenças por uma variedade de meios que sobrecarregam o sistema imunológico e danificam ou destroem o tecido vivo.

Os patogênicos em sistemas sanitários que apresentam risco, geralmente estão relacionados com a fração fecal e não com a fração da urina. Por isso é muito importante evitar ou minimizar a contaminação cruzada com a fração de urina. A contaminação fecal cruzada pode ocorrer pela disposição errada das fezes no sanitário separador de urina, diz respeito aos riscos mais significantes para a saúde (SCHONNING e STENSTRON, 2004).

Do momento em que a excreta deixa o corpo e antes que os patógenos tenham acesso ao meio ambiente, existem várias opções de prevenir a disseminação de doenças. O enfoque tradicional é enviá-las através do sanitário de fluxo de água acionando a descarga. O que acontece é que com este método, nem sempre, se estará evitando a contaminação do ambiente, pois na maioria das vezes as águas negras não recebem o devido tratamento, sendo lançadas diretamente nos cursos de água acarretando graves danos ambientais.

Os sistemas convencionais de tratamento de esgotos baseados na utilização de água para o transporte dos dejetos são particularmente inadequados para destruir os patogênicos, pois a água residual é um ambiente ideal para a sobrevivência de patógenos, pois equivale, em muitos casos, aos intestinos humanos. É rica em matéria orgânica, nutrientes, anaeróbia e a temperatura opera abaixo de $37^{\circ} \mathrm{C}$ (ESREY et al., 1999).

Uma opção de saneamento ecológico que apresenta condições para que os excrementos sejam coletados e armazenados favorecendo a ação dos microorganismos são os sanitários secos (DEL PORTO e STEINFELD, 2000). Os sanitários secos não utilizam água para seu funcionamento. As fezes e urina são coletadas e armazenadas em câmaras que podem utilizar o processo de compostagem ou desidratação como tratamento primário dos excrementos visando sua reciclagem.

Os sanitários secos podem ser classificados em: sanitários de compostagem, onde o princípio básico é promover a decomposição biológica dos excrementos humanos por processos aeróbios (CALVERT et al., 2004) e sanitários de desidratação, onde o princípio básico é secar ou evaporar as fezes.

Como afirmam Esrey et al (1999), a desidratação consiste em retirar toda a água contida no material armazenado na câmara. Isto é conseguido com calor, ventilação e a adição de um material secante. A umidade deve ser reduzida para a diminuição dos patógenos e a ausência de odores e moscas. O desvio da urina é importante, pois a redução de líquidos na câmara facilita a desidratação das fezes.

O processo de desidratação apresenta algumas vantagens em relação aos sanitários de compostagem. A principal delas é que o processo de desidratação é menos complexo que o processo de compostagem, resultando em menor necessidade de manutenção. Outra vantagem é que o produto resultante de um banheiro de desidratação é mais seco que o de compostagem, sendo, portanto mais fácil de manusear.

Os sanitários secos ainda podem ser classificados como auto-coletores ou centralizados e ainda podem ser compostos por câmara única ou duas ou mais câmaras intercambiáveis. Estas tecnologias podem ainda ser industrializadas ou construídas no local. O modelo industrializado ou pré-fabricado é aquele pode ser comprado e obedece a normas e padrões enquanto que o construído no local pode estar sujeito a dificuldades de conseguir permissão do órgão e agentes de saúde local (DEL PORTO e STEINFELD, 2000).

Os banheiros podem funcionar através de sistemas passivos ou ativos. Sistemas passivos são geralmente reatores simples de decomposição no qual a mistura de excrementos, papel higiênico e aditivo é coletada e colocada para decompor em ambientes frescos sem ser controlada por processos ativos (aquecimento, mistura e aeração). Os sistemas ativos podem exibir misturadores automáticos, aparelhos niveladores da pilha de matéria orgânica, aquecedores acrescidos de termostatos, ventiladores etc. (DEL PORTO e STEINFELD, 2000). 
Um exemplo de sistema ativo pode ser visualizado na Figura 3. Este modelo que comporta a utilização de 7 a 9 pessoas para casas de fim de semana ou férias e de 4 a 6 pessoas para uso residencial, possui uma câmara compostadora central, o material compostado é transferido horizontalmente a medida que ele vai sendo processado. Uma barra interna é responsável pela mistura do material. O chorume é drenado para uma câmara em baixo da câmara central e é aquecido por um sistema elétrico gerando a evaporação do mesmo (ALVES, 2009).

Figura 03: Banheiro seco de sistema pré-fabricado, ativo. (a) Modelo Centrex $3000 \mathrm{AF}^{\oplus}$ da SunMar. (b) Aplicação de modelos centralizadores em edifícios de mais de um pavimento

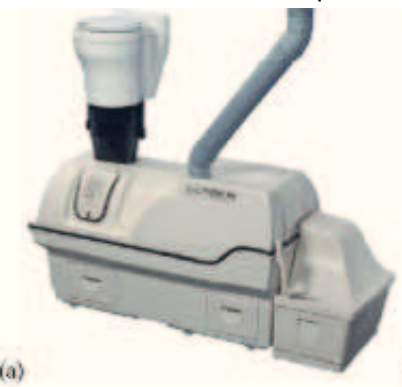

(b)

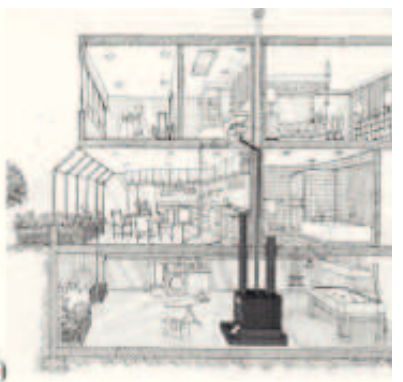

Fonte: Alves, (2009)

Analisando o tipo do assento ou vaso sanitário, observa-se que este pode funcionar como o sistema convencional, ou seja, as fezes e urinas são depositadas nas câmaras por meio de um único orifício, portanto armazenadas juntamente, ou depositadas em orifícios diferentes. Os aparelhos que possibilitam esta separação são chamados Urine divert toilets (UDTs), e consistem em um assento ou vaso especial que ajuda a separar as fezes da urina, que é dirigida a um coletor separado.

Existem diversos exemplos de sistemas de saneamento seco em operação demonstrando que esta tecnologia apresenta condições de ser utilizada nos mais diversos contextos. Observam-se aplicações em pequena e grande escala, assim como sua inserção tanto em espaços rurais como urbanos. Um exemplo é condomínio ecológico New- Allermoe, localizado no sudeste da cidade de Hamburgo na Alemanha, este condomínio compreende 34 habitações unifamiliares (Figura 4) totalizando 120 moradores.
Figura 04: Imagem das residências e corte mostrando o sistema de banheiro seco e a tubulação de ventilação
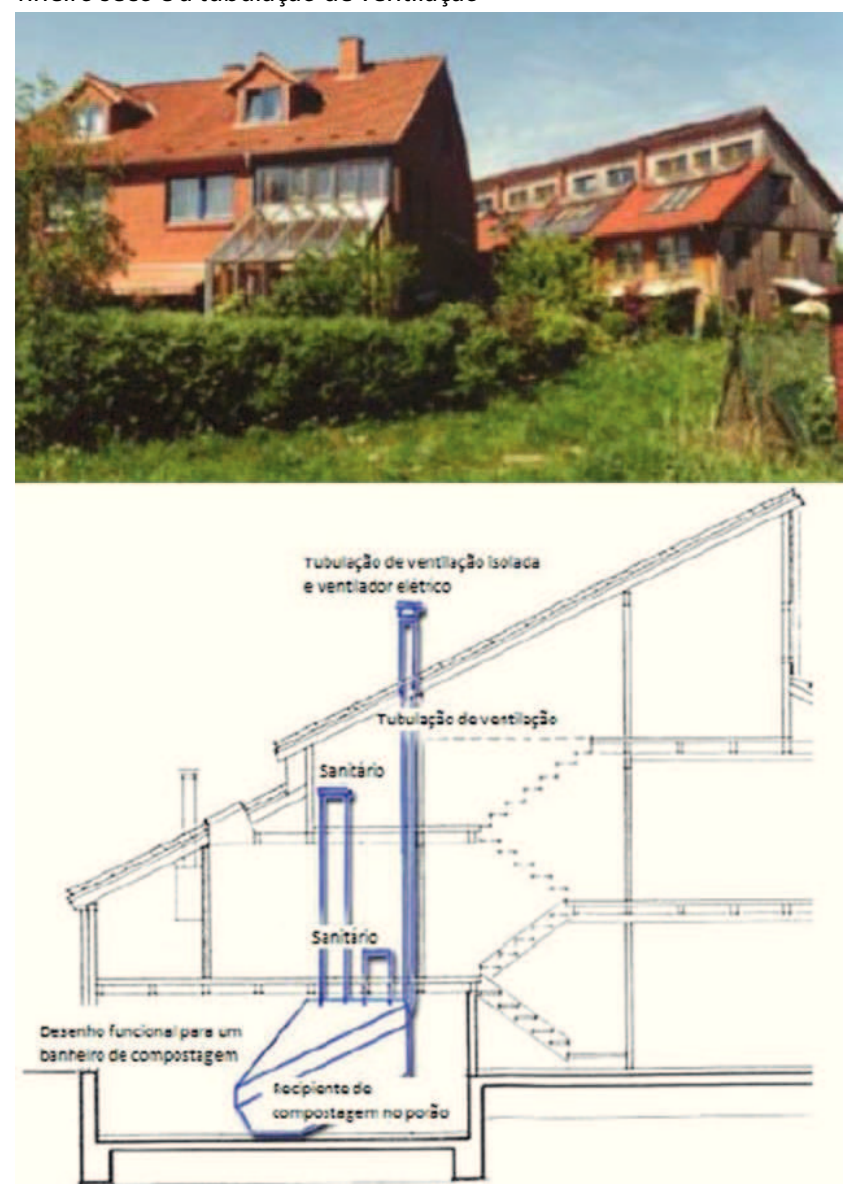

Fonte: Jurga et al., (2006)

Outro exemplo de implantação de um sistema industrializado de sanitário seco é o zoológico de Asahikawa, localizado na parte central da ilha de Hokkaido no Japão (Figura 5). A região não é coberta por um sistema de esgoto, e o projeto tem por objetivo substituir os problemas causados pelo uso de sanitários convencionais. (HUELGAS et al., 2006).

Figura 05: Sistema automatizado de sanitário seco

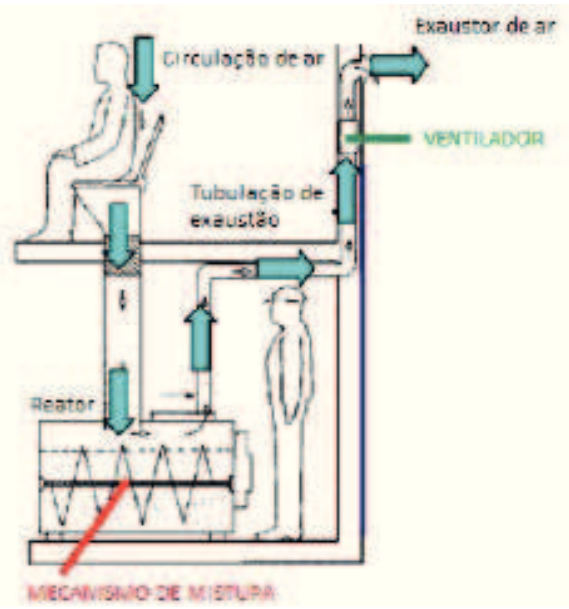

Fonte: Huelgas et al., (2006) 
Além destes modelos industrializados, podemos observar a utilização de tecnologias não automatizadas como este projeto na China, onde uma cidade inteira foi projetada para funcionar com sanitários secos. O projeto está localizado no Vilarejo de Haozhaokuidistrito de Dongsheng município de Erdos, no interior da Mongólia, norte da China (Figura 6). Dongsheng é uma cidade com uma população estimada de 400.000 habitantes e uma área de $2.200 \mathrm{~km}^{2}$.

Figura 06: Prédios da cidade e corte demonstrando a tubulação e coletores móveis
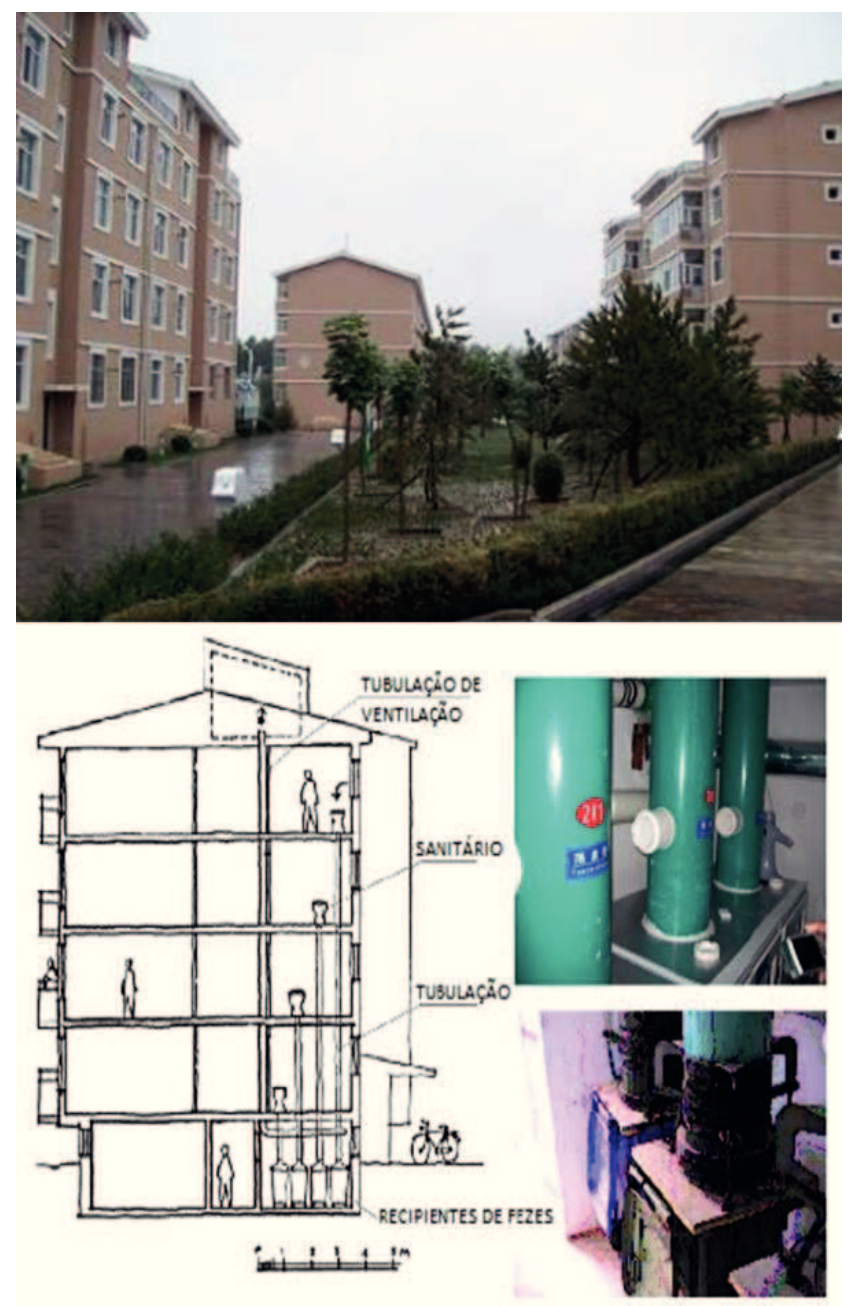

Fonte: Zhu, (2006)

\section{MÉTODO DA PESQUISA}

Através de um enfoque qualitativo de pesquisa, procurou-se descrever os parâmetros projetuais para a implantação de Sanitários Secos Desidratadores com Desvio de Urina como estratégia de saneamento mais sustentável. Para isso foram utilizadas técnicas de pesquisa de campo e bibliográfica-documental. Na pesquisa de campo foram realizados estudos de caso através de entrevista estruturada com visitas em locais que implantaram banheiros secos como sistema de saneamento e por meio de consulta bibliográfica aos formulários fornecidos pela SuSana. A consulta aos formulários fornecidos pela SuSanA, se fez necessária pela falta de exemplares em potencial a serem analisados disponíveis no contexto brasileiro e pelo vasto material sistematizado no assunto disponibilizado pela Aliança de Saneamento Sustentável relatando experiências aplicadas em diversos países.

A Amostragem da pesquisa compreende os seguintes locais:

- Instituto Çarakura (Figura 07) - Florianópolis, SC, Brasil (visita ao local);

Figura 07: Vista externa da sede do Instituto Çarakura e detalhe dos sanitários

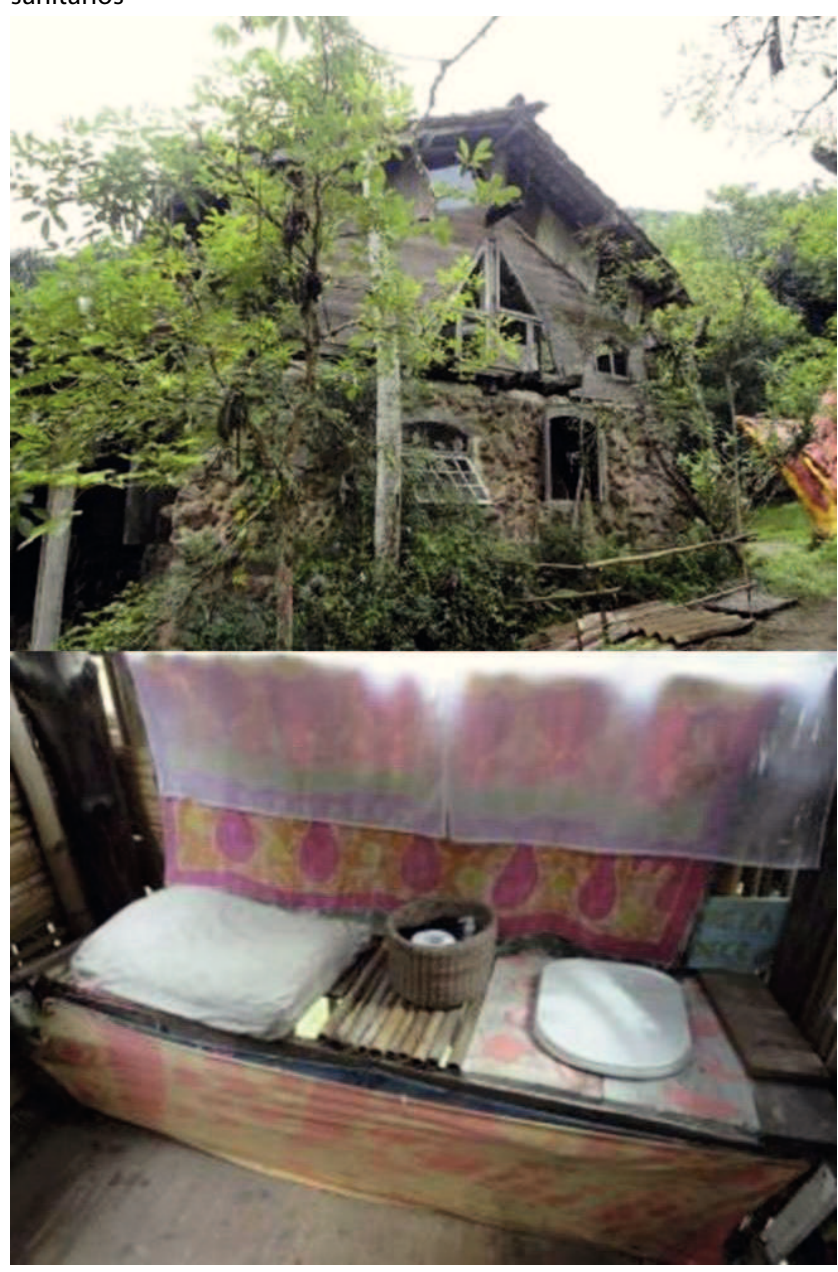

Fonte: Autores

- Empresa de Pesquisa e Extensão Rural de Santa Catarina - EPAGRI (Figura 08) - Universidade Federal de Santa Catarina - UFSC, Florianópolis, SC, Brasil (visita ao local); 
Figura 08: Superestrutura para o sanitário seco e vaso segregador - EPAGRI

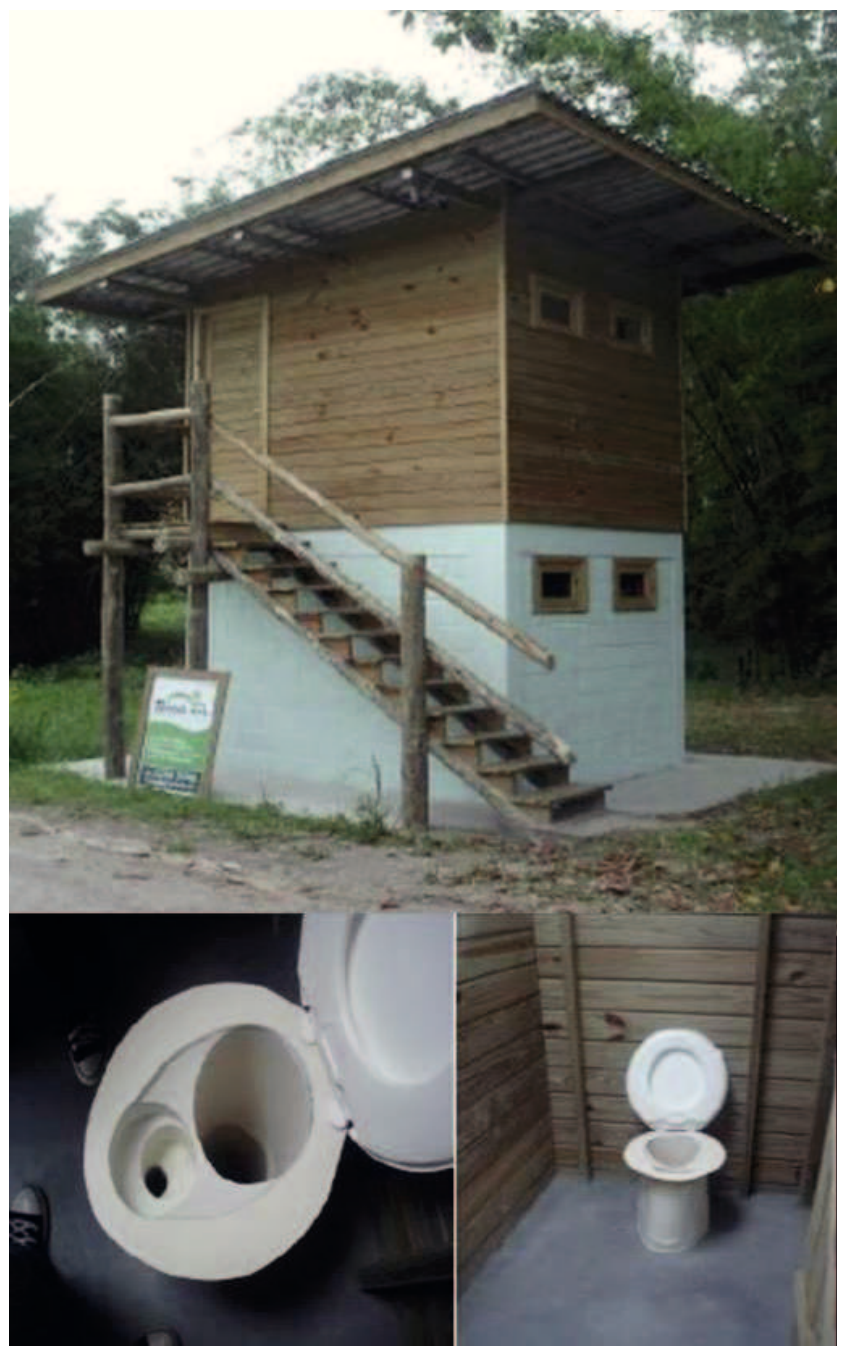

Fonte: Autores

- Comunidade Rural - Província de Shaanxi, China (Figura 9), pesquisa bibliográfica;

Figura 09: Modelo de sanitário tipo cócoras implantado na comunidade rural da China

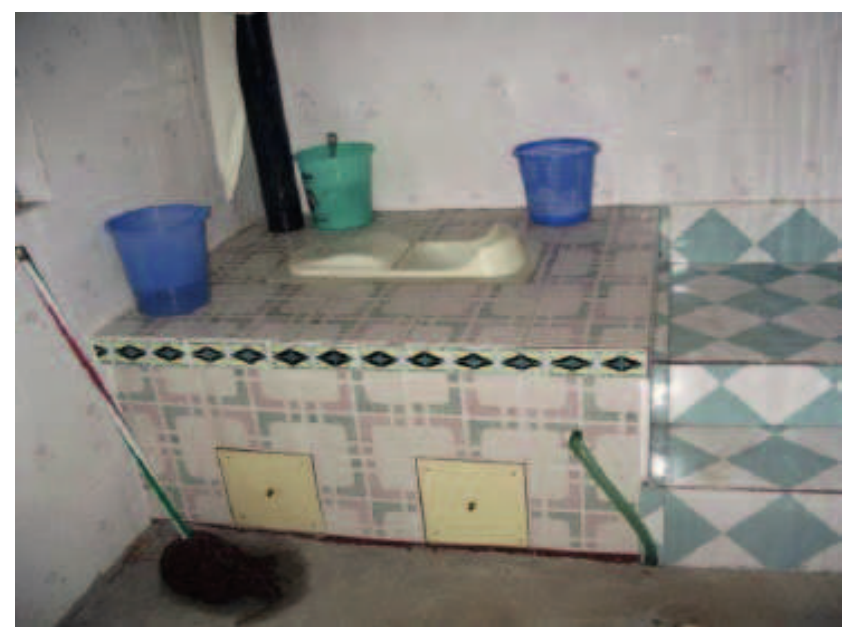

Fonte: Kumar, (2008)
- Escola Rural - Hayanist, Armênia (Figura 10), pesquisa bibliográfica;

Figura 10: Modelo de sanitário tipo cócoras implantado na comunidade rural da China
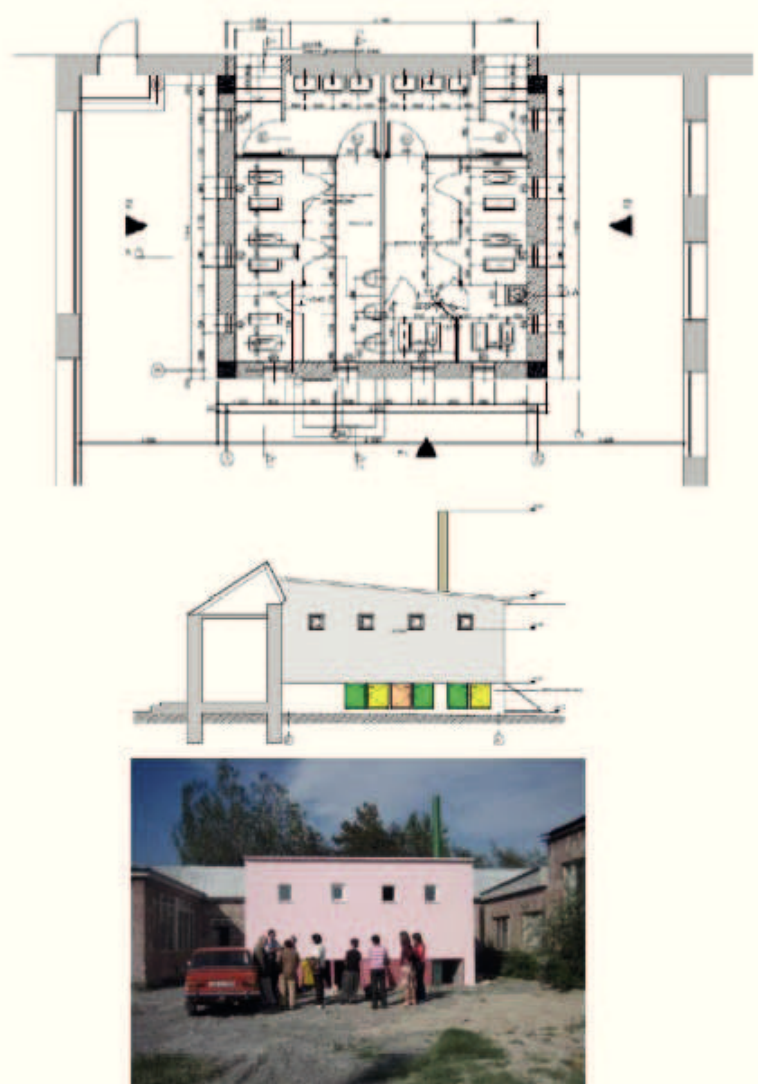

Fonte: Deegener et al., (2009)

No estudo de caso foram levantadas questões relativas ao tipo de sistema que foi aplicado no local, assim como aspectos relacionados à construção do equipamento, materiais utilizados e questões relativas à operação e manutenção.

A pesquisa bibliográfica-documental focalizou suas atenções sobre livros, artigos e manuais que abordaram não só a questão da degradação do meio ambiente, principalmente da contaminação do solo e recursos hídricos, mas também do uso de sanitários secos como alternativa de saneamento ecológico.

A pesquisa qualitativa pelos tipos de técnicas que emprega não apresenta delimitação estanque entre a coleta e a interpretação das informações obtidas. Existe um fluxo constante entre as informações levantadas e, em seguida, interpretadas, podendo surgir novas buscas de informações. Portanto, embora haja uma fase distinta com a denominação "análise", na medida em os dados vão sendo colhidos a análise poderá estar ocorrendo.

Desta forma, os dados obtidos foram confrontados com as informações colhidas durante a revisão 
bibliográfica e sintetizados para a formulação dos parâmetros projetuais propostos.

\section{PARÂMETROS PROJETUAIS PARA IMPLANTAÇÃO DE SANITÁRIOS SECOS DESIDRATADORES COM DESVIO DE URINA}

Um Sanitário Seco Segregador é composto pelos seguintes elementos: superestrutura, bacia segregadora, sistema de coleta e armazenamento da urina, câmara para armazenamento das fezes, tubulação para ventilação como podem ser visualizados na Figura 11.

Figura 11: Elementos de um sanitário seco segregador

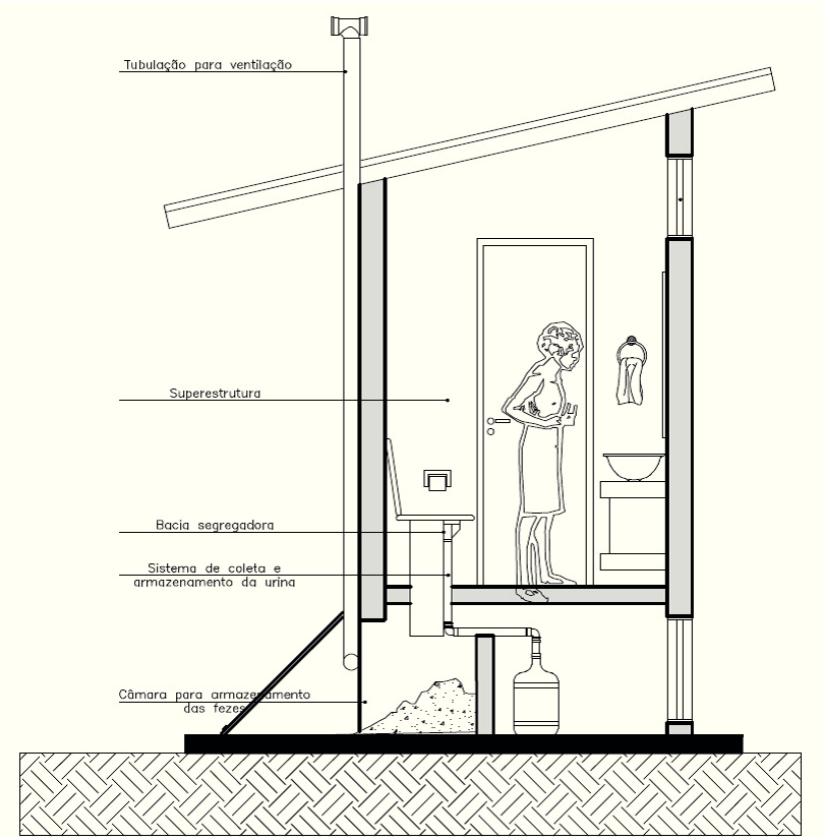

Fonte: Autores

\subsection{Componentes do projeto para a superes- trutura de um SSDDU}

A superestrutura oferece privacidade e conforto para os usuários. Para isto recomenda-se que o espaço mínimo apropriado para que o usuário possa se movimentar considerando o sistema de duas câmaras com assentos intercambiáveis seja de $160 \mathrm{~cm}$ de largura e $120 \mathrm{~cm}$ de comprimento, e cada assento colocado a uma distância de pelo menos $30 \mathrm{~cm}$ das paredes (Figura 12).
Figura 12: Espaço mínimo sugerido para colocação dos assentos

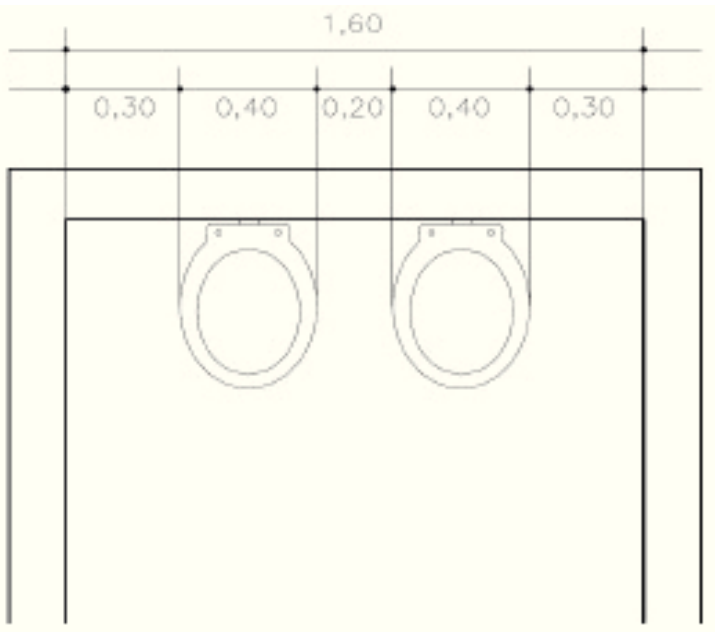

Fonte: Autores

Para a limpeza do ambiente, o piso deve ter uma superfície lisa e durável. Este espaço deve ter uma inclinação suficiente para drenar a água para fora do ambiente. Isto pode ser conseguido com a instalação de um ralo na cota mais baixa. É importante assegurar que a água não entre no compartimento das fezes.

\subsection{Bacia Segregadora}

A bacia segregadora tira proveito da anatomia do corpo humano que é de excretar a urina e as fezes separadamente, portanto ambas as substâncias podem ser coletadas de forma independente. A urina é recolhida através de um pequeno orifício na área frontal do assento enquanto que as fezes caem através de um buraco maior na parte traseira do assento. Assim o usuário precisa se posicionar de forma que a coleta seletiva seja feita. Existem bacias segregadoras tipo pedestal disponíveis no mercado, mas quando isso não é possível e a fim de reduzir os custos de implantação, esta pode ser confeccionada nos mais diversos materiais. Um modelo do tipo pedestal com tubos de Policloreto de vinila (PVC) pode ser confeccionado com dois tubos de diferentes diâmetros, unidos entre si como mostra a Figura 13. 
Figura 13: Exemplo de bacia segregadora

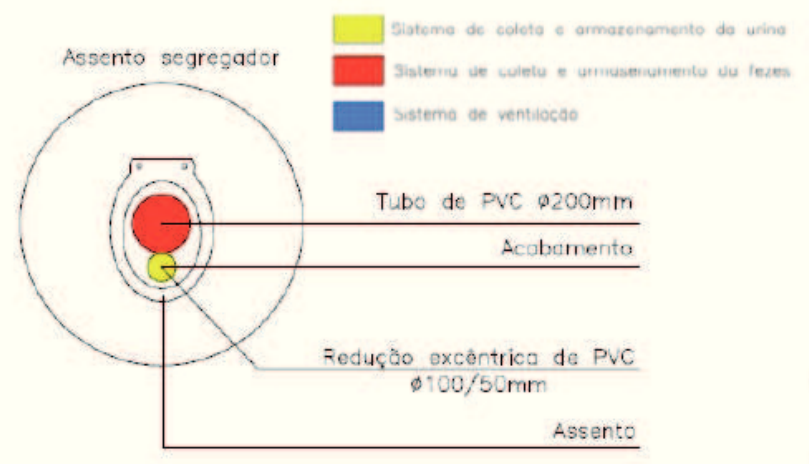

Fonte: Autores

\subsection{Componentes do projeto do sistema de co- leta da urina}

O sistema de coleta da urina tem o objetivo de drenar a urina para um sistema de armazenamento para fins de reutilização ou para a sua eliminação por meio de infiltração subterrânea. Os tanques de armazenamento têm a finalidade de higienizar a urina através do armazenamento, ou simplesmente aguardar o momento em que ocorre a fertilização das plantações ou a espera por um prestador de serviços para ser esvaziada.

Para calcular o volume do recipiente de armazenamento da urina (equação 1), multiplicamos a taxa diária de produção de urina por pessoa pelo número de dias de armazenamento desejado.

$$
\mathrm{VTu}=\mathrm{Nu} \times \mathrm{Vu} \times \mathrm{Tarm}(1)
$$

Sendo:

$\mathrm{VTu}=$ Volume do tanque de urina

$\mathrm{Nu}=$ Número de usuários

$\mathrm{Vu}=$ Volume de urina excretado por pessoa/dia*

Tarm $=$ Tempo de armazenamento

* Para estimativa da produção de urina a ONU recomenda adotar a média de 1,5 litros pessoa/dia

Tanques de até 20 litros são frequentemente utilizados para um armazenamento em curto prazo, pois são facilmente transportados, porém o esvaziamento deverá ser feito com maior frequência. Tanques de tamanhos intermediários podem ser utilizados alternadamente oferecendo um tempo maior de armazenamento. Porém recomenda-se não utilizar tanques com dimensões muito grandes pela dificuldade de transporte.

Para o perfeito funcionamento da tubulação de urina devem ser evitados os bloqueios que podem ser causados pelo uso indevido, como o ato de defecar no coletor de urina, ou pela queda acidental de materiais como cinzas ou outros materiais.
Para evitar bloqueios na tubulação de saída da urina podemos utilizar um diâmetro pequeno para a captação entre 50 a 110 mm com uma tubulação subseqüente maior. Assim evitamos a entrada de objetos indesejáveis e também subentendemos que este não e o local apropriado para o depósito de fezes. A utilização de uma peneira removível no orifício de coleta também pode ajudar na filtração, porém esta peneira precisa ter uma limpeza regular.

Recomenda que o comprimento da tubulação não ultrapasse 10 metros, as curvas devem ser evitadas sempre que possível, nos locais onde a curvatura seja necessária podem ser utilizadas aberturas para a inspeção para evitar bloqueios na tubulação. Além disso, devem possuir boa vedação não permitindo vazamentos e a proteção de vandalismo ou quebras acidentais quando expostas em ambientes externos. A inclinação mínima recomendada é de $4 \%$.

Os materiais para tubulação devem ser preferencialmente de material plástico como o Policloreto de vinila (PVC) ou o Polietileno (PE), o metal é um material que deve ser evitado para a tubulação e armazenamento da urina por apresentar efeitos corrosivos, a preferência é por mangueiras mais rígidas para evitar curvaturas acentuadas que podem bloquear a tubulação.

No caso em que a urina é armazenada em tanques, os odores podem chegar ao sanitário por meio do sistema de tubulação, para isso torna-se necessário ventilar o tanque, porém isto pode afetar a qualidade do fertilizante, pois parte do nitrogênio é perdido pela emissão de amônia, em geral a emissão de amônia é a causa dos odores.

\subsection{Componentes do projeto do sistema de co- leta e armazenamento das fezes}

Um sanitário seco desidratador padrão é composto por duas câmaras intercambiáveis. Apenas uma câmara é utilizada até que esteja cheia depois se começa a utilização da outra câmara. $\mathrm{O}$ uso de duas câmaras permite o "descanso" da matéria fecal durante vários meses (6 -12 meses), promovendo a secagem e a desidratação.

As câmaras podem ser construídas no local ou feitas com recipientes plásticos como bombonas, porém nestes últimos, observa-se frequentemente a tendência de compactação do material, criando condições de anaerobiose, por esse motivo, recomenda-se que se dê preferência por câmaras construídas no local, pois proporcionam um material mais seguro para ser manuseado.

Para as câmaras construídas no local, a localização acima do solo é importante para evitar infiltrações do 
material e a contaminação do lençol freático além de proporcionar melhor acesso para a retirada do material das câmaras após o armazenamento. Deve construir na base uma laje de pelo menos $10 \mathrm{~cm}$ acima do solo para proteger de inundações.

O piso não precisa necessariamente ser impermeabilizado, mas deve apresentar uma inclinação de pelo menos $1 \%$ em direção à porta da câmara a fim de direcionar possíveis líquidos. Um dreno deve ser posicionado em área anexa ao sanitário, que apesar da lixiviação ser reduzida pelas condições das fezes secas pode existir por algum resíduo de urina ou outros líquidos. Em áreas sujeitas a alagamentos as câmaras devem ser posicionadas acima destas cotas.

Antes da primeira utilização, deve-se cobrir o chão da câmara com uma espessa camada de $3 \mathrm{~cm}$ de terra seca para absorver a umidade e impedir a aderência das fezes no piso.

As câmaras devem obedecer sempre que possível a orientação solar norte e evitar locais sombreados, pois a radiação ajuda atingir temperaturas mais elevadas auxiliando o processo de secagem. Portas construídas com inclinação de $45^{\circ}$ de material metálico favorecem as condições de secagem. Neste caso é importante proteger as câmaras da entrada de água da chuva com vedações.

O dimensionamento da câmara vai depender do número de usuários e a frequência de utilização. A equação abaixo apresenta como podemos obter o volume por pessoa para um período de armazenamento de 6 meses, para isto deve-se multiplicar o número de usuários pelo volume conforme a equação 2 :

$$
\mathrm{VCf}=\mathrm{Nu} \times 35 \text { Litros* }^{*}(2)
$$

Sendo:

$\mathrm{VCf}=$ Volume da câmara de fezes

$\mathrm{Nu}=$ Número de usuários

*Para estimativa do volume das câmaras por pessoa foram considerados os seguintes dados:

Recomenda-se utilizar uma altura livre de $20 \mathrm{~cm}$ acima da massa dentro da câmara, pois a distribuição ao longo da pilha pode ocorrer de forma desigual acumulando-se em um ponto.

\subsection{Tubulação para ventilação}

As câmaras não devem ser hermeticamente fechadas, pois o suprimento de ar e a ventilação são benéficos para o tratamento. A ventilação dentro da câmara fornece a exaustão dos odores e da umidade. Por isso sempre deve ser previsto um sistema de ventilação, mesmo em climas secos. A ventilação pode ser natural ou mecânica. $A$ ventilação natural consiste em posicionar um tubo de pelo menos $100 \mathrm{~mm}$ de diâmetro que por meio do efeito sifão leva os odores para fora do ambiente. Podem ser metálicos ou de plástico, e devem ultrapassar $1 \mathrm{~m}$ acima do telhado.

Na saída do tubo deve-se prever uma cobertura para impedir a entrada da água da chuva. Também uma armadilha para evitar a penetração de insetos é necessária. Para isso ser conseguido podemos utilizar uma grade ou malha como na Figura 14.

Figura 14 - Exemplo de armadilha para insetos

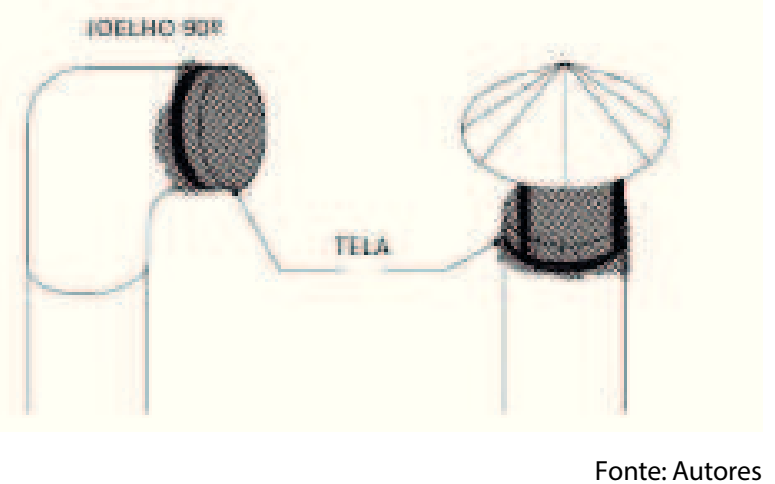

\subsection{Operação do sistema}

Para o controle de odores, recomenda-se borrifar água no orifício de captação da urina, para a tubulação de fezes podemos utilizar tampas, que além de bloquear visualmente o material da câmara impedem que os odores emanem do tanque de armazenamento. Além disso, o ambiente deve ser bem ventilado.

As tampas podem ser operadas com os pés, evitando o contato manual reduzindo o risco de transmissão de doenças. Além disso, tampas removíveis podem se perder ou serem quebradas em determinados ambientes.

Já para o assento que não está sendo utilizado, as tampas devem ser fixas, com o objetivo de inutilizar seu uso e com a função de proporcionar o descanso do material dentro da câmara. Pequenas quantidades de urina e sangue menstrual não causam problemas, o papel higiênico deve ser depositado dentro da câmara ao contrário de absorventes íntimos e outros produtos de higiene que devem possuir um recipiente a parte, pois não são biodegradáveis e devem ser tratados como resíduos sólidos. Outros resíduos como restos de cozinha, guardanapos e outros detritos não devem ser depositados na câmara, pois podem interferir no processo de desidratação devido seu teor de umidade.

Para controlar os odores no interior das câmaras de 
fezes devemos manter níveis de umidade baixos, isto é conseguido com a adição de material secante, recomenda-se a utilização de uma mistura de $50 \%$ conchas e ostras trituradas e $50 \%$ de cinzas na proporção de $75 \%$ do peso das fezes úmidas.

\subsection{Recomendações para a eliminação segura do material gerado}

Embora não seja âmbito da pesquisa, a abordagem dos métodos de tratamento para reuso de fezes e urina humanas, algumas recomendações para gestão dos subprodutos gerados serão apresentadas a fim de minimizar o risco de transmissão de doenças.

Como afirmam Schonning e Stentrom (2004), para residências familiares a urina pode ser usada sem armazenamento prévio para todo tipo de cultivo, desde que os cultivos para o consumo sejam para a mesma residência e que tenha transcorrido um mês entre a fertilização e a colheita, ou seja, o tempo entre a última aplicação da urina e o consumo, os autores ainda afirmam que se deve evitar diluir a urina durante o armazenamento. A urina concentrada proporciona um ambiente mais adverso para os microorganismos e aumenta a taxa de decaimento dos patógenos.

Schonning e Stentrom (2004) ainda afirmam que a urina deve permanecer em um tanque fechado ou container. Isto previne que pessoas e animais entrem em contato com a urina e impede a evaporação da amônia, reduzindo assim o risco de odores e a perda de nitrogênio disponível para as plantas.

Porém, os possíveis metabolitos humanos como os hormônios podem ainda persistir. A bibliografia ainda não apresenta dados significativos que comprovem sua utilização segura, por isso, recomenda-se que a urina seja infiltrada no solo através de um poço de absorção. Este poço pode ser um buraco de 1,5 a $4 \mathrm{~m}$ de profundidade, dependendo da quantidade da urina e as propriedades de absorção do solo. O buraco pode ser preenchido com pedras grossas ou cascalho ou deixado vazio.

Já para as fezes, o tratamento secundário pode compreender um tratamento alcalino, a co-compostagem, a incineração e o armazenamento. Segundo Schonning e Stenstron (2004), o armazenamento é a forma mais simples de tratamento das fezes. A inativação de patógenos geralmente é lenta. Para realizar uma higienização segura do produto, alcançando um fertilizante de uso seguro, é necessário um tempo de armazenamento variando de meses para a redução bacteriana, até anos para alguns helmintos. Observa-se que este monitoramento muitas vezes não é conseguido em uma escala residencial. Por isso, como afirma Rieck (2011), para a utilização a nível domiciliar, a recomendação é que o material gerado não seja colocado na superfície do solo, e sim enterrado, coberto por uma camada de terra de no mínimo $30 \mathrm{~cm}$ para evitar o contato com seres humanos e animais e por risco de erosão. O local deve estar acima do lençol freático e com certa distância de poços de captação de água. A utilização deve ser de forma produtiva como para o plantio de árvores frutíferas, arbustos e outras plantas que possam fazer uso dos nutrientes, evitando o uso para legumes e os tubérculos.

\section{REFERÊNCIAS}

ALVES, B. S. Q. Banheiro seco: análise da eficiência de protótipos em funcionamento. Monografia (Ciências biológicas) - UFSC, Florianópolis, 2009.

CALVERT, P.; MORGAN, P.; ROSEMARIN, A.; SAWYER, A.; $X I A O, J$. Ecological sanitation. Stockolm Environment Institute, Stockholm, Sweden, 2004.

DEEGENER, S.; SAMWEL, M.; ANAKHASYAN, E. UDDT toilets in rural school Hayanist, Armenia. Case study of SuSaNa projects. SuSaNa, 2009. Disponível em: <www. susana.org> . Acesso em: out. de 2010.

DEL PORTO, D.; STEINFELD, C. Composting toilet system book: A practical guide pollution to choosing, planning, and maintaining composting toilet systems. Center of Ecological Prevention, Concord, 2000.

ESREY, S.; WINBLAD, U.; GOUGH, J.; RAPAPORT, D.; SAWYER, R.; HEBERT, M.; VARGAS, J. Ecological sanitation. Swedish International Development Cooperation Agency, Stockholm, Sweden. 1999.

GONÇALVES R. (Coord.). Uso racional da água em edificações. Rio de Janeiro: Projeto PROSAB - ABES, 2006.

HARREMOES, P. (1999). Water as a transport medium for waste out of towns.

HEEB, J.; JENSSEN, P.; GNANAKAN, K.; CONRADIN, K. Ecosan systems and technology components. IEES, 2007.

HUELGAS, A.; TERRAZAWA, M.; SCHICK, J.; RATH, N.; WERNER, C. Automated composting toilet system at Asahiyama Zoo. Data sheets for ecosan projects. GTZ, 2006. Disponível em:<www.gtz.de/en/dokumente/ 
enecosan-pds-030automatedcomposttoiletasahiyama-zoo-2006.pdf>. Acesso em: out. de 2011.

JÖNSSON, H.; STINTZING, A; VINNERAS, B.; SALOMON, $E$. Guidelines on the use of urine and faeces in crop production. EcoSanRed Programme, Stockholm Environment Institute, Sweden, 2004. Disponível em: <www.ecosanres.org>. Acesso em: mar. de 2011.

JURGA， I.; SCHLICK， J.; KLINGEL， F.; BRACKEN， P.; WERNER, C. Ecological settlement Allermoehe Hamburg. GTZ. Alemanha, 2005. Disponível em: <www. giz.de>. Acesso em: ago. de 2011.

KUMAR, P. Community - led water and ecosan programme Shaanxi province, China. Case study of SuSanA projects. GTZ, Ecosan program, 2008. Disponível em: <www.susana.org>. Acesso em: out. de 2011.

MORGAN, P. Toilets that make compost. stockholm environment institute. Harare, Zimbabwe, 2007. Disponível em: <www.ecosanres.org/pdf_files/ ToiletsThatMakeCompost.pdf>. Acesso em: jul. de 2010.

SCHÖNNING, C.; STENSTRÖM, T.A. Guidelines on the safe use of urine and faeces in ecological sanitation systems. EcoSanRes Programme and Stockholm Environment Institute. Estocolmo, Suécia, 2004. 40p.

ZHU, Q. Introduction to Erdos eco-Town project. GTZ. Eschborn, 2006. 